\title{
Research on the Development Mode of Ecological Agriculture Based on the Theory of Circular Economy
}

\author{
Liu Yingyuan \\ School of Economics and Management, Hubei University of Technology, Wuhan, 430068, China \\ Email:2500207860@qq.com
}

Keywords: circular economy; agricultural circular economy; development mode of ecological agriculture

\begin{abstract}
In china, the basic status of agriculture and problems occurring during its development process determine the importance of circular economy mode in agriculture. After giving a brief overview of circular economy theory, this paper compares the circular economy and the traditional economy on the background of putting forward optimization model of agricultural circular economy and for its advantages. Besides, this paper describes and discusses the concept, connotation, principle and characteristics of agricultural circular economy, and finally interprets the development mode of ecological agriculture based on circular economy theory from three aspects, namely, scientific and technological innovation, market-oriented industrialization upgrading and social system improvement.
\end{abstract}

\section{Introduction}

Since the last century, the circular economy has been put forward by Baldin, Chinese scholars have also done several researches about it. Professor Zhu Dajian of Tongji University believes that the circular economy is a new kind of earth friendly economy; it requires that all of the raw materials and energy can be reasonably utilized in the ongoing economic cycle, so the impact of economic activities on the natural environment could be controlled as much as possible. While Zhang Tianzhu thinks that circular economy is not only a kind of feedback mechanism which make its internal materials circulate all the time but also a kind of economic development system which can integrate into the large ecological material cycle system. And this circular economy is established according to the resource metabolism cycle model of "resources-production and consumption-renewable resources". ${ }^{[1]}$ Dai $\mathrm{Li}$ believes that circular agriculture is to apply the concept of circular economy into agricultural production. In the process of agricultural production and in its products life cycle, circular agriculture could reduce resource input and waste emissions so as to achieve the unification of agricultural economy and ecological environmental benefits. ${ }^{[2]}$ On the basis of protecting the agricultural ecological environment and making full use of new technology, the adjustment and optimization of the internal structure and industrial structure of agricultural ecosystem could improve the multi-level recycling of materials in agricultural system and strictly control the input of external harmful substances and agricultural waste emissions. Then the positive cycle of ecology and sustainable development of agricultural economy could be achieved. Li Zhiqiang thinks that agricultural circular economy is to apply the concept of circular economy into agricultural system, reduce the input of resources and waste emissions in agricultural production process, then achieve the win-win of agricultural economic and ecological environmental benefits

\section{The connotation and principle of circular economy}

Circular economy takes the efficient utilization and recycling of resources as the core, it has the basic characteristics of "low consumption, low emissions and high efficiency", it is also the radical transformation of the traditional development $\mathrm{p}$, which refers to "high consumption, high emission, 
high pollution, high production and low efficiency". ${ }^{[3]}$ Applying ecological laws, it reconstructs economic activities into a "resources - products - renewable resources" feedback process and "low mining-high utilization-low emissions" recycling model, making the economic system harmoniously integrated into the natural ecosystems , maximizing the resources utilizing efficiency in order to achieve the ecologicalization of economic activities and eliminate environmental pollution and finally improve the quality of economic development. In a word, the circular economy not only changed the traditional way of economic growth, but also changed the traditional mode of production and consumption.

The rapid development of circular economy is good for radically solving two major problems faced by the traditional economy, namely, the problem of resource scarcity and environmental pollution. ${ }^{[4]}$ Developing circular economy refers to the maximization of economic benefits with the least resource consumption which can better protect the environment, which can be reflected by its principles:

(1) Circular economy follows the principle of "reduction" and aims at minimizing the input of resources.

(2) Circular economy follows the principle of "reuse" and aims at maximizing the utilization of waste.

(3) Circular economy follows the principle of "recycling” and aims at minimizing pollution emissions.

\section{Comparison analysis of circular economy model and traditional economic model}

The operating model of circular economy refers to the circulation and transformation of materials in economic activities. ${ }^{[5]}$ Before the emergence of circular economy, the economic mode of human society is purely linear. More detailed, after entering the production process, resources and energy are processed and transformed into finished products. After consuming these products, the waste is discharged into environment, thus polluting the environment. This whole process can be expressed by a formula: production-consumption-wastes (Figure 1). This economic model is the common one existing in current economic society, which is usually called the traditional economic model.

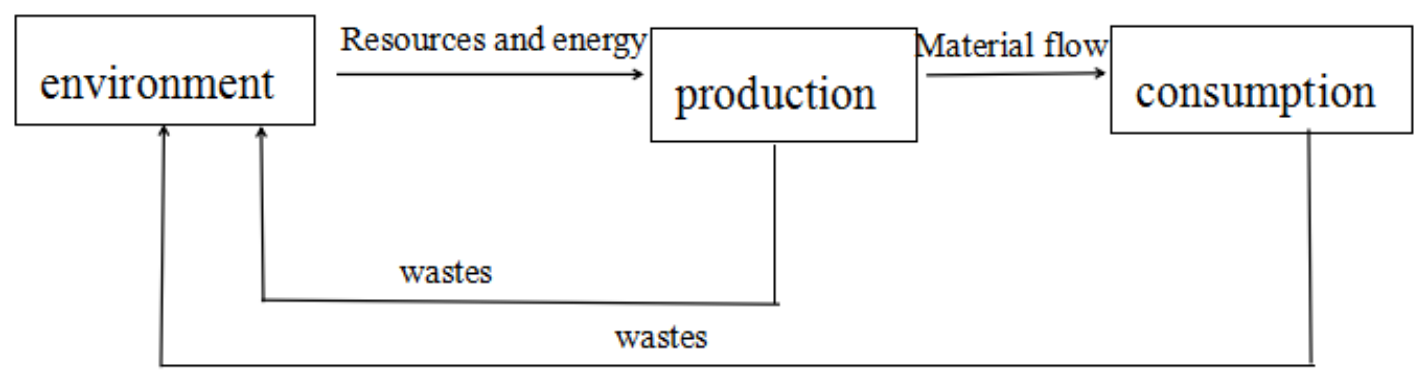

Figure 1 Traditional economic mode

Compared with traditional economic, the circular economic model is carried out according to the material transferring mode of the natural ecosystem. An ideal natural ecosystem is a kind of semi-open system which only exchanges energy with outside world, and it follows the process of "energy-ecosystem". In circular economy, part of materials are transformed into substances that human beings can use while other part become wastes after they are produced and consumed in human economic system. Actually, after the second time processing, these materials could become useful resources again, plus there would be only a few substances which can influence human environment. Therefore, the circular economy is a kind of economic model which can save resources and protect environment. 


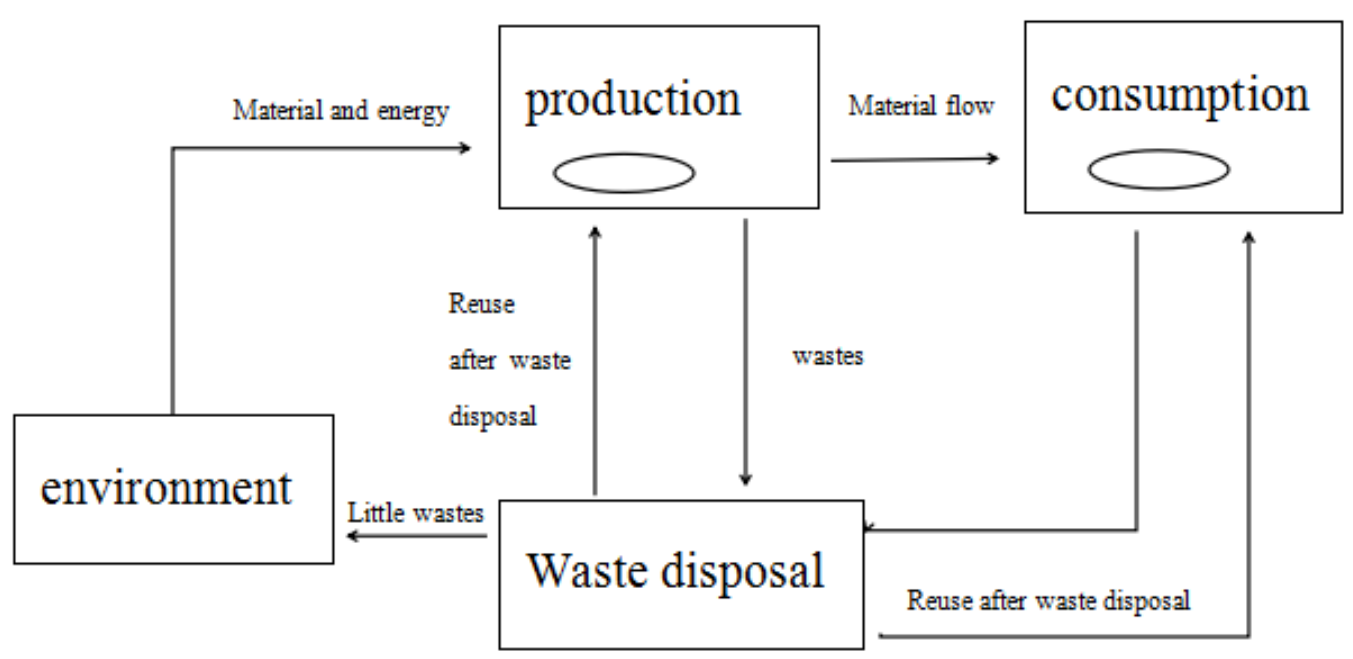

Figure 2 Circular economy model

\section{About agricultural circular economy}

\subsection{Definition}

Applying the circular economy concept into agricultural system and drawing support from today's high-tech achievements, the agricultural circular economy is a kind of environmentally harmonious economic development model. ${ }^{[6]}$ It can reduce the input of materials in its producing process and its life cycle, reduce the waste emissions, and set up a closed circulation of materials within the agricultural production system to bring dual benefits to agricultural economy and ecological environment.

\subsection{Characteristics}

First of all, as a kind of circular economy, the agricultural circular economy has its general characteristics, which is mainly manifested in that it is different from the traditional economic development model. The traditional economy is a kind of one-way development model. The materials in traditional economy follow the path of "resources - products - unloading". While circular economy is a kind of recycling developmental model, the materials producing follow the path of "resources - products -renewable resources" on the basis of constant and circulatory use of resources. In this whole producing and consuming process, there are only very few or basically no wastes.

Then, the agricultural circular economy also has the characteristics that the general circular economy does not have. The first one is food chain. The objects that are involved in the circulation of agriculture are usually food for each other. They circulate in the form of the ecological food chain. Each one in the cycle is complementary, co-existing and co-benefiting. The second one is green production. It emphasizes the safety of products, controls the application of fertilizers and pesticides, and appropriately uses environment-friendly "green" agrochemicals to minimize environmental pollution. The third one is technology improvement. In agricultural circular economy, high and new technology is used for optimizing the structure of agricultural system. So the production has a feedback process of "resources-agricultural productions-agricultural wastes-reborn resources". The fourth one is soil and water purification. The soil and water is the basis of everything. Special attention should be paid to the protection and sustainable utilization of soil, arable land and water resources. The agricultural circular economy should focus on the improvement of agricultural production environment and the protection of farmland biodiversity, and regard them as the foundation for sustained and stable development of agriculture. The fifth one is the extension of agricultural eco industrial chain. By recycling and factors coordination, agriculture and other industries could have a co-developing situation which not only including the 
circulation of agricultural production but also including the recycling of agricultural wastes.

\section{The development mode of ecological agriculture under the theory of circular economy}

The development model of ecological agriculture is a comprehensive agricultural development model, which is formed by the integration of the agricultural economic development system and agricultural ecosystem. Though theoretically, the agricultural economic system and the agro-ecosystem can be separated from each other. In practice, the two subsystems continue to exchange material, energy, value and information. In the framework of agricultural circular economy system, agricultural ecological system is in a basic position comparing to agricultural economic system, while agricultural economic system must respect and comply with the natural rule of the agricultural ecosystem. The close cooperation between them helps to promote the benign operation of the ecological agriculture development model.

\subsection{Increasing government investment and promoting scientific and technological innovation of agriculture}

The government should increase the investment of the industrialization of ecological agriculture, especially the investment in the innovation of agricultural science and technology. To achieve this, the government could provide large amount of funds to allow more people to invest in the basic research of agriculture, or to establish relevant key laboratory, engineering research center, and production-study-research technology innovation alliance with the help of universities and research institutions. In addition, the government could also set up a research and development institution integrated with scientific research, trial production and production. Supported by suitable theory, technological innovation platform and advanced agricultural producing technology and equipment referenced or imported from abroad, the government could provide high-tech agricultural production for farmers and cultivate new farmers with high quality.

\subsection{Promoting the market-oriented agricultural ecology and industrialization upgrading}

The industrialization of ecological agriculture cannot be separated from market; otherwise, there will be no high economic benefits. Therefore, ecological agriculture must be market-oriented, and establish the dominant industry, then vigorously support the leading enterprises or key enterprises, which can construct an industrialization model of ecological agriculture integrating agriculture, industry and commerce together. In this way, farmers could timely and accurately access to market information and build up their marketing conception, then the whole developing process could be promoted. Without doubt, the market dominated ecological agriculture would urge farmers to produce healthy food including green food, organic food, pollution-free food and ecological food. Besides, every link of production should be environmentally friendly, healthy and pollution-free. At last, having the aid of rural regional advantages, we should also vigorously publicize healthy foods; promote the brand building of agricultural products, so as to achieve the transformation and upgrading of eco agriculture.

\subsection{Strengthening the construction of rural infrastructure and build social service system in rural areas}

In the process of eco agricultural industrialization, we should strengthen propaganda and education, strengthen farmers' awareness of environmental protection, and develop eco industry in an all-round way. We should also avoid blindly following the trend. Instead, we should choose the leading industry scientifically and optimize the model of eco agriculture. All these should be based on a perfect socialized service system in the countryside. Therefore, we should strengthen the agricultural infrastructure construction, increase farmers' income and strive to build a rural service system which integrates agricultural information, technology, finance, materials, personnel, intermediary service together. In this way, agricultural production could be centralized and then become specialized, unified and socialized. Having the complete infrastructure facilities and perfect social service system in rural areas, we should help farmers to improve the overall efficiency of 
agricultural management, promote comprehensive competitiveness, and realize the sustainable and leaping development.

\section{Conclusion}

Agricultural development in China is undergoing a critical transformation period. The current industrialization of eco-agriculture which is based on the circular economy model exactly caters to the development requirement of "low-carbon agriculture and green economy". According to the principle of circular economy, we must constantly improve productivity and comprehensive agricultural production capacity, promote cleaner production and carry out comprehensive utilization of agricultural wastes. On this basis, the overall coordination of other several factors, such as social and economic policy, humanistic thought, system innovation, scientific and technological innovation and structural adjustment is also needed. The development of agricultural circular economy in China should follow the "entirety, harmonization, circulation and regeneration" principle. Under China's existing conditions, we should have the development model which is suitable for China agricultural region, such as build up the scientific development mechanism of "Policy guarantee, technology support, bibcock-driving", positioning on local conditions and holistic planning. Only in this way can we gradually form a sustainable development model of ecological agriculture under the circular economy system.

\section{References}

[1] Group studies eco-industrial parks. Defendis,M. Waste News. 1998

[2] Economic-environmental monitoring indicators for European countries: A disaggregated sector-based approach for monitoring eco-efficiency [J]. Sibylle Wursthorn, Witold-Roger Poganietz, Liselotte Schebek. Ecological Economics. 2010 (3)

[3] The role of conservation agriculture in sustainable agriculture [J]. Hobbs Peter R, Sayre Ken, Gupta Raj. Philosophical Transactions of the Royal Society B. 2007 (1491)

[4] Analysing the evolution of industrial ecosystems: concepts and application [J]. Ecological Economics. 2004 (2)

[5] Advanced agricultural biotechnologies and sustainable agriculture [J]. Thomas A Lyson. Trends in Biotechnology. 2002 (5)

[6] TIM: Assessing the sustainability of agricultural land management [J]. C.S Smith, G. T McDonald, R.N Thwaites. Journal of Environmental Management. 2000 (4) 